\title{
МЕЖДУНАРОДНО-ПРАВОВОЕ РЕГУЛИРОВАНИЕ ОБЪЕДИНЕНИЙ ПО АЛМАЗАМ: ВОЗМОЖНОСТИ И ПЕРСПЕКТИВЫ
}

\author{
A.E. Б е ля е в $^{*}$
}

Мировой рынок сырьевых товаров до Второй мировой войны находился под господством международных картелей. В 1934 году была создана Центральная сбытовая организация (ЦСО), которую называют международным алмазным картелем. Если говорить точнее, сама ЦСО полностью находится под контролем одной частной компании - "Де Бирс", которая ведет переговоры и заключает договоры о реализации алмазов через ЦСО с государствами и частными компаниями. Основу ЦСО составляет Diamond Trading Company (DTC). Эта компания осуществляет продажу алмазов сайтхолдерам (клиентам "Де Бирс") через шестерых алмазньх брокеров. Сейчас примерно 160 компаний десять раз в году получают приглашения участвовать в алмазньх торгах в Лондоне, Люцерне или Йоханнесбурге, где им предлагаются боксы (ящики) алмазов стоимостью от 10 миллионов долларов США каждый.

Картель первоначально объединил алмазодобывающие компании Южной Африки, Анголы и Конго. Механизм атмазного картеля называется единым каналом сбыта (single channel). Разразившийся в 1930-х годах мировой экономический кризис привел к “обвалу” алмазного рынка. “Де Бирс" закрыла все свои рудники и на протяжении почти 20 лет ЦСО снабжала рынок продукцией из ангольских и конголезских источников. В годы Второй мировой войны международный алмазный картель отверг заявку правительства США на покупку крупной партии технических алмазов для военных нужд. Все попытки американской дипломатии оказать давление на "Де Бирс" через правительство в Лондоне провалились. "Де Бирс" заявила, что она не в состоянии обеспечить требуемый объем поставок, и предложила встречные условия, которые оказались неприемлемы для США' ${ }^{1}$ Против "Де Бирс" было начато судебное преследование в связи с нарушением антимонопольного законодательства, и деятельность компании в США была запрещена. Так как антимонопольное законодательство США не задевало зарубежные операции “Де Бирс", в целях обеспечения Соединенных Штатов техническими алмазами были ускорены исследования по производству синтетических алмазов, и в 1950-х годах "Дженэрал Электрик" начала их производство ${ }^{2}$. После Второй мировой войны в США был создан также Оборонный национальный резервный центр (Defense National Stockpile Center), создавший резерв и природных технических алмазов.

В 1950 году алмазный картель объявил эмбарго на поставку алмазов Советскому Союзу. Поставщики алмазов социалистическим странам

\footnotetext{
*Аспирант кафедры международного права МГИМО(У) МИД РФ.
} 
лишались доступа $\mathrm{k}$ новым алмазам или вынуждены были покупать алмазное сырье в два раза дороже ${ }^{3}$.

В 1954 году были обнаружены первые экономически перспективные месторождения алмазов в СССР, в 1957 году началась промышленная добыча советских алмазов. В авторитетном Pick's World Currency Report в марте 1956 года о советской торговле атмазами писали: "We believe that they will handle them the same as they do gold - sell at the best world market prices"4. Обнаруженные в Сибири алмазы были хорошего ювелирного качества, но не годились для оборонной промышленности из-за большого содержания пузырьков газа в них. "Де Бирс" предложила сделку: продажа Советским Союзом алмазов через ЦСО и снятие эмбарго на поставку алмазного инструмента в социалистические страны. В 1960-1963 годах ВТО "Союзпромэкспорт" заключает первые контракты с "Де Бирс" о продаже алмазов.

До 1990-х годов ЦСО осуществляет продажу до $95 \%$ всех добываемых алмазов в мире. Первый серьезный удар по картелю был нанесен другой ТНК - "Рио Тинто", контрапирующей крупнейшпй в мире атмазный рудник “Аргайл”, добываюший 1/3 алмазов. В 1996 году "Аргайл” начал самостоятельый маркетинг своих алмазов посте $11 \%$ снижения ЦСО цен на его продукцию в рамках картеля ${ }^{5}$. В настоящее время международный апмазный картель контролирует продажу примерно $70 \%$ всех атмазов ${ }^{6}$.

Литература по картелям едина в том, что мировой алмазный рынок способствует созданию картеля и деятельность его нуждается в поддержке со стороны государств ${ }^{7}$. Таким образом, алмазный картель может суцествовать только как международный, и только с участием государств. В своем исследовании по международно-правовому и антимонопольному регулированию международных соглашений по сырьевым товарам Т. Веберпалс (Weberpals) дает определение сырьевому картелю как “добровольное объединение частных предприятий с целью совместного контроля одного сырьевого товара посредством планомерного воздействия на предложение или производство этого сырьевого товара. Если объединенные предприятия находятся в разных странах, речь идет - межтународном сырьевом картеле"в. В нашем случае алмазный картель - это добровольное объединение частньх предприятий и государств с целью совместного контроля алмазного рынка.

Отношения в алмазном картеле предусматривают:

- систему квот (в процентах от годовых продаж ЦСО);

- фиксацию цены, увязанную с квотой и ситуацией на рынке;

- обязанность продаж апмазов только через единый канал сбыта;

- положение о преимущественном праве ЦСО на покупку производимых сверх квот алмазов.

Сейчас в международный алмазный картель входят правительства и/или компании Ботсваны, Намибин, Танзании, России, Гвинеи, ДРК (бывшего Заира), Зимбабве, Китая, Анголы, Австралин, Канады.

Ключевыми факторами функционирования этой системы в настоящее время, как отмечает сама "Де Бирс", являются:

- взаимозависимость, существующая между "Де Бирс" и крупнейшими производителями, связанными единым каналом сбыта для сохранения ИХ доходов от алмазов; 
- сотрудничество "Де Бирс" с правительствами Ботсваны и Намибии, которые вместе являются крупнейшим в мире производителем алмазов с возможностью дальнейшей экспансии;

- инвестиции группы "Де Бирс" в анализ и исследования, что сохраняет ее лидерство в добыче и торговле алмазами;

- финансовая сила “Де Бирс", которая позволяет как образовывать буферный запас алмазов, так и активно скупать их на открытом рынке с целью балансирования спроса и предложения;

- эффективный сбыт с прибылью для всех производителей через сеть международных клиентов “Де Бирс", состоящую из крупнейших в мире огранциков; и

- успех всемирной рекламной компании “Де Бирс" по рекламе бриллиантовых украшений в 34 странах с бюджетом 200 миллионов долларов США в год 9 .

Реалией современного рынка алмазов является то, что публикуемые ЦСО монопольные цены на алмазы служат основой для установления нижней границы цен на алмазы во всем мире. В то же время организация международного алмазного рынка противоречит основным принципам международной торговой системы - недискриминации, свободе торговле и конкуренции. Анализ данной ситуации остается за пределами нашего рассмотрения.

В середине 1990-х годов Россия выступила с инициативой создания объединения государств-производителей алмазов, поддержанной правительствами ЮАР, Ботсваны и Намибии. С российской стороны в переговорах участвовал председатель Комитета РФ по драгоценным металлам и драгоценным камням, который провел переговоры с президентами Ботсваны и Намибии и вице-президентом ЮАР. В дальнейшем к переговорному процессу присоединилась Антола. В 1998 году между Россией и Намибией и Анголой соответственно были заключены соглашения о сотрудничестве в области развития алмазньх комплексов, в которьх содержатся положения о том, чего нет: стороны договариваются проводить консультагии по вопросам участия в межтосударственньх и международныгх организациях и обьединенных стран - производителей драгоценныхх камней. Учитывая, что эти соглашения офищиально не публиковались, остается только сожалеть, что мы не имеем возможности обходиться без информации “Де Бирс" и других немногих компаний, при том, что во всей сфере алмазов работает 2 миллиона человек, и, как говорится, шила в мешке не утаишь. К тому же эти соглашения на затрагивают права и обязанности государств обеспечивать в соответствии со своим законодательством защиту информации, имеющей отношение $\mathrm{K}$ интересам национальной безопасности. Более раннее соглашение России с Китаем о сотрудничестве в развитии алмазо-бриллиантовьх комплексов двух стран также выпадает из нашего рассмотрения. Оставляя практику за пределами дапнейшего рассмотрения, обратимся к теории объединений государствпроизводителей сырьевьх товаров.

Все государства имеют право объединятвся в организации производителей товаров для развития своей национальной экономики и достижения стабильного финансирования своего развития. Данное положение содержится в статье 5 Хартии экономических прав и обязан- 
ностей государств 1974 года. Все государства обязаны уважать это право, воздерживаясь при этом от применения таких экономических или политических мер, которые ограничивапи бы это право. То же самое относится к транснациональным корпорациям. Деятельность ТНК не должна создавать условия, которые противоречат интересам принимающего государства. Хотя международно-правовое регулирование деятельности ТНК осуществляется нормами так называемого "мягкого права", так как они не являются субъектами МП, можно говорить о признании данного регулирования государствами в результате неоднократного его подтверждения в документах ООН. Наиболее ранним из таких документов, действуюшим до сих пор, является резолюция ГА ООН А/1803 (XVII) "О суверенитете над природными ресурсами" от 14 декабря 1962 r.

После Второй мировой войны было подписано около 20 соглашений стран-производителей сырьевьх товаров, в том числе заключенных на региональной основе ${ }^{10}$. Среди них - Совет стран-экспортеров меди (Council of Copper Exporting Countries), Конференция стран-производителей бокситов (Conference of Bauxite Producing Countries), a также объединения по ртути, урану, железу, железной руде и т.д. Хотя межтосударственные объединения производителей сырьевых товаров могут называться "Конференцией", "Советом", "Ассоциацией" и т.Д., их структура и функции во многом схожи. Наиболее известным и наиболее успешным объединением государств-производителей сырьевых товаров является Организация стран-экспортеров нефти (ОПЕК). Несмотря на то, что рассматриваемые об́единения производителей сырьевых товаров являются объединением государств, для обозначения этих соглашений многими, в том числе учеными, стал неправомерно использоваться термин "картель". Использование этого термина имело, вольно или невольно, целью "подвести” объединения государств-производителей под действие антимонопольного законодательства. В 1978 г. в США Международная ассоциация пилотов и работников аэропортов (International Association of Machinists and Aerospace Workers) обратилась в суд с требованием признать установление ОПЕК цен на нефть нарушающим антимонопольное законодательство США. Суд отказался рассматривать иск, применив доктрину "the act of state". Как уже отмечалось, картель гредставляет собой частноправовое образование, объединяющее компании (и государства) с целью совместного контроля рынка одного сырьевого товара. "Экспортный картель, - как пишет Миқдашш в исследовании, посвяшенном ОПЕК, - не только должен включать жесткие соглашения по ценам, но также соответствуюшие соглашения в таких ключевьх областях, как контроль производства и раздел рынка. Экспортный картель должен также выполнять мониторинг деятельности своих членов с целью предотврашать нарушения и наказывать нарушителей. Государства-члены ОПЕК не выполняот ни одну из этих фуншиий. Их соглашенпя по экспортнњм ценам на нефть строго добровольны... Более того, соглашения оставляют на усмотрение каждого государства установление и изменение цен в диапазоне, определяемом как разумный, членами ОПЕК" 11 . ОПЕК устанавливает своим членам квоты дневной добычи нефти, соблюдение которьх также добровольно.

ОПЕК была создана в 1959 г. пятью государствами. В 1964 г. уже 
ОПЕК заключила соглашения с крупнейшими нефтяными компаниями ${ }^{12}$. Но данные компании в ОПЕК не вошли. Таким образом, налицо международно-правовая природа самого межгосударственного объединения производителей, в данном случае ОПЕК.

Главными целями межгосударственньх объединений производителей сырьевых товаров являются обеспечение приемлемых цен на их продукты и получение справедливых доходов от инвестиций в соответствуюшие отрасли сырьевых товаров. Целями также могут быть охрана окружаюцей среды, обеспечение стабильности цен на соответствуюшие сырьевые товары, повышенде эффективности сырьевых отраслей и оптимизации ресурсов, повышение квалификации в соответствующих отраслях путем обмена специалистами и т.д.

В рамках межгосударственньх объединений производителей сырьевых товаров проводятся:

- совместный фиксинг цен;

- совместный маркетинг;

- рыночные ассигнования;

- обмен информацией;

- согласование мер по национальному контролю за компаниями-производителями (роялти, цен и минимаљьњх ставок налогообложения);

- согласование производственных квот и экспортных лимитов.

Для осуществления контроля за мировым рынком алмазов достаточно соглашения семи основных государств-производителей: Австралии, Анголы, Ботсваны, ДРК, Намибии, России и ЮАР. В этом особое значение такого объединения для России, которая производит 20\% мировой добычи алмазов в стоимостном выражении. Ни по одному другому сырьевому товару у России нет такого выгодного положения в межгосударственнњх экономических отношениях.

Основной целью объединения стран - производителей алмазов, таким образом, является достижение и поддержание справедливых и выгодных цен. Механизмом для достикения этой цели, учитывая международный опыт, может быть система квот. В настоящее время существует определенная угроза перепроизводства алмазов: к 2001 году Ботсвана должна увеличить свое производство на $1 / 3$, рост добычи ожидается также в Россин, Анголе, Канаде. В стучае с алмазами существует еще особенность квотирования. Необработанные апмазы (сырье) классифицируются как industrial diamonds, так назыпаемые "индийские алмазы" (near-gems) и драгоценные камни ювелирного качества (gems) ${ }^{13}$. Австралия добыла в 1996 г. 42 миллиона карат алмазов, Россия - 13 миллионов карат. В то же время алмазный экспорт Австралии был оценен в 600 миллионов долларов США, а российский экспорт - в два раз больше. Российские алмазы - более высокого качества. Девяносто процентов намибийских алмазов - это алмазы ювелирного качества. В Антале $70 \%$ алмазов оцениваются как ювелирного качества, $20 \%$ - как "индийские алмазы" и только $10 \%$ как технические. В целом мировая добыча алмазов вкпочает $80 \%$ технических и "индийских" алмазов и 20\% - ювелирного качества, в то же время эти $20 \%$ образуют $80 \%$ стоимости всей алмазодобычи ${ }^{14}$. Не учитъвая различия в качестве добываемвх алмазов, государства могут оказаться втянутыми в беспредметные переговоры. 
Третьей, и может быть самой сложной проблемой для возможного объединения государств-производителей алмазов станет создание буферного алмазного резерва. Частногравовое регулирование алмазного рынка привело к образованию международным картелем многомилииардного резерва алмазов. Создание буферных резервов предусматривается также и некоторыми межтосударственными соглашениями по сырьевым товарам. В финансировании создания алмазного резерва государств смог бы оказать содействие ряд международных организаций, в том числе МВФ. Фонд уже предложил содействие Ботсване для уменышения ее зависимости от алмазной промышленности.

Усиление международно-правового регулирования рынка сырьевых товаров привело к тому, что многие бывшие сырьевые картели заменены межтосударственными соглашениями по сырьевым товарам ${ }^{15}$. Учитьвая то, тто данное регулирование считается основнњд для международньх рынков сырьевых товаров, наше рассмотрение без него было бы неполным.

Международные соглашения по сырьевым товарам являются многосторонними международно-правовыми договорами между государствами-экспортерами сырьевых товаров и государствами-импортерами этих товаров. Предметом регулирования международнњх соглашений по сырьевым товарам являются оборот первичньх сырьевьх товаров, то есть товаров, поставляемых без дальнейшей обработки на мировые рьпки.

Обшая цель международных соглашений по сырьевым товарам обеспечение всеобщей стабилизации на рынках сырьевых товаров. Среди конкретных целей: достижение справедливых и выгодных цен на сырьевые товары для государств-производителей и государств-потребителей; стабилизация доходов от экспорта развиваюшихся стран $^{16}$; содействие улучшению положения с сохранением окружающей среды в странах добычи, улучшению условий жизни, сохранению невосполнимых ресурсов; сокращение времени реагирования на изменения на рынке и т.д. Проблемность целей международных соглашений по сырьевым товарам заключается с одной стороны в концепции "стабилизации", с другой - в определении "справедливых и выгодных цен на сырьевые товары". В отношении "стабилизации" можно привести цитату Мейера: "Стабилизация может относиться к международной цене экспортируемого сырьевого товара, к валютным или реальным доходам производителей, $\mathrm{k}$ доходам от экспорта, или $\mathbf{K}$ покупательной способности экспорта сырья по отношению к импорту. Неизбежная трудность схемы контроля сырья cocтоит в том, что при стабилизации одной из этих переменных величин (например, цены) она может в то же самое время дестабилизировать другую переменную величину (например, доходы от экспорта)" ${ }^{17}$. Справедливые и выгодные цены после Второй мировой войны понимались как цены, которые будут обеспечивать “меры для расширения мирового потребления сырьевых товаров"18. ЮНКТАД поставила задачу стабилизации цен на "высоком уровне", но увязала рост цен на сырьевые товары с индексацией цен на сырьевые товары в соответствии с развитием цен на товары, импортируемые развиваюшимися странами. Тақхм образом, международные соглашения по сырьевым товарам в зависимости от международной практики могут 
быть оценены как механизм регулирования и компенсации колебаний цен на сырьевые товары вокруг усредненной цены или как форма помощи развивающимся странам ${ }^{19}$.

Все международные соглашения по сырьевым товарам имеют идентичную организацию. Инструментарием их являются:

- системы экспортных квот;

- буферные резервы ${ }^{20}$;

- многосторонний долгосрочный контракт, фиксирующий минимальную цену, по которой страны-импортеры согласны покупать определенные объемы, и максимальную цену, по которой страныпроизводители согласны экспортировать установленный объем;

- ежегодные консультации, анализы рынка, статистика.

На четвертой конференции ЮНКТАД в 1976 г. в Найроби (ЮНКТАД-ГV) была принята резолюция 93 об интегрированной программе по сырьевым товарам. Критерием включения сырьевого товара в Интегрированную программу являлось наличие "экспортного интереса развивающихся стран". Интегрированная программа предусматривала создание Совместного фонда для финансирования регулирования сырьевых товаров с первоначальным капиталом от 10 млрд. до 13 млрд. долларов США. Соглашение о создании Совместного Фонда было подписано в июне 1980 г., в июне 1989 г. оно вступило в силу ${ }^{21}$. Согласно Соглашению о Фонде его средства предоставляются для мер по улучшению структурньх условий на рынках и долтосрочный конкурентоспособности отделыных сырьевых товаров, в том числе мер по вертикальной диверсификации (ст. 18.3 а Соглашения).

Таково рамочное международно-правовое регулирование оборота сырьевых товаров. Практика международных отношений доказывает, что в целом эффективное регулирование рынков минеральных сырьевых товаров посредством соглашений по сырьевым товарам трудно осуществимо, несмотря на существование Совместного фонда и поддержку МВФ. Это можно объяснить во многом общей тенденцией на снижение мировых цен на сырьевые товары. В то же время заинтересованность в подобном регулировании остается. В целом межтосударственные объединения производителей сырьевых товаров показали себя более эффективными, чем международные соглашения по сырьевым товарам.

Продолжая сравнение, можно с уверенностью сказать, что международный алмазный картель остается сейчас наиболее эффективньм механизмом обеспечения стабильности мирового алмазного рынка. В то же время данный аргумент - плохой ориентир для международно-правового регулирования. Цель государств - социально-экономическое развитие национальньг обществ в целом, и международное право отражает интересы наций, которые включают все аспекты, в том числе и международного оборота алмазов. Для примера, эффективное картельное регулирование в Африке осуществляется на фоне войн во всех странах-производителях алмазов, кроме Ботсваны, Намибии и ЮАР. Несомненно, что международный картель не может иметь задач, противоречащих национальной политики государств, но он и не может действовать экономически неэффективно. Международное объединение государств-производителей алмазов может себе позволить мень- 
шую экономическую эффективность, в том числе для достижения большей политической стабильности.

I B то же время рудник De Beers "Formini' ere" в бельгийском Конго предположительно продавал технические алмазы нацистам. См. Kanfer $S$. The last empire: De Beers, diamonds, and the World. - N.Y., 1993, p. 239. Для справки: тогдашний глава "Де Бирс" сэр Э. Оппенгеймер родился на территории Германии в г. Фридберге, где еврейская община была почти полностью уничтожена в годы войны. В существующем ныне музее, который посетил автор, есть маленький памятник Э. Оппенгеймеру.

2 Синтетические атмазы составляют сейчас $90 \%$ предложения на рынке технических алмазов.

${ }^{3} \mathrm{CM}$. Gregory T. Ernest Oppenheimer and the Economic Development of Southem Africa. - London, 1962 , p. 324.

4 "Мы думаем, что они будут торговать ими так же, как они торгуют золотом - продавать по лучшим мировым ценам". Pick's World Currency Report, 1956, March, p. 13.

5 "Де Бирс" выразила после этого сожаление по поводу ряда банкротств, прошедших в Индии, куда постављется большая часть продукции “Аргайл”. De Beers. Annual Report 1996, p. 11.

${ }^{6}$ Вне картеля осуществляют маркетинг свокх алмазов Австрапия, Бразилия, Венесуэла, Гана, Гвинея, Сьерра-Леоне.

7 Kempton D.R./Levine R.M. Soviet and Russian Relations with Foreign Corporations: The Case of Gold and Diamonds. American Slavic Rewiev. 1997, Summer.

${ }^{8}$ Weberpals $T$. Intemationale Rohstoffabkommen im Volker - und Kartelrecht. Munchen, 1989, S. 19.

${ }^{9}$ CM. De Beers. 1996 Annual report, p. 3.

${ }^{10} \mathrm{CM}$. Вельяминов Г.M. Основы международного экономического права. M., 1994. - C. 29.

${ }^{11}$ Mikdashi. The OPEC Process, 104 Deadalus No., 207-208 (Fall 1975). Цит. по Henkin L./Pugh R.G./Schachter O./Smit H. Intemational law. Cases and materials. St. Paul, Minn, 1987, pp. 343-344.

${ }^{12}$ C. . Ashworth F.G. International commodity control: a contermporary history and appraisal. Цит. по Henkin, pp. 982-986.

${ }^{13}$ В России и других государствах СНГ для обозначения industrial diamonds используется термин "технические алмазы".

${ }_{14}$ CM. Buschgen H.E. Das kleine Borsenlexikon. - Dusserldorf, 1998, p. 233.

15 CM. Weberpals S. S. 19.

16 С конца 1970-х годов эта цель рассматривается в контексте внешней задогженности развивающихся стран. См. IMF Survey, 1984, Dec. 10, p. 370.

17 Meier. UNCTAD proposals for international economic reform. Цит. по Jackson J.H./Davey W.J. Legal problems of intermational economic relations. Cases, materials and text on the national and international regulations of transnatonal economic relations.

- St. Paul, Minn, 1986, p. 973.

18 Ст. 63(a) Гаванской Хартии 1948 г.

19 Meier. Там же. - C. 974.

20 Буферные резервы надо отличать от "железньх резервов", величина которьх неизменна.

21 Соглашение ратифицировали 104 государства.

Статья поступила в редакцию в январе 1999 г. 